\title{
Investigating Factors Affecting Intention to Use Mobile Payment Among Young Professionals in Malaysia
}

\author{
Shaizatulaqma Kamalul Ariffin* \\ Graduate School of Business \\ Universiti Sains Malaysia \\ Penang, Malaysia \\ shaizatulaqma@usm.my
}

\author{
Khor Teik Lim \\ Graduate School of Business \\ Universiti Sains Malaysia \\ Penang, Malaysia \\ khorteiklim@yahoo.com
}

\begin{abstract}
This paper is to investigate the factors that influence intention to use of mobile payment among young professionals in Malaysia. Theory acceptance model and Theory of planned behavior had been integrated to investigate this phenomenon. Five factors (perceived ease of use, perceived usefulness, attitude, subjective norms, perceived behavioral control) were tested on intention to use mobile payment. In addition, trust was added to the framework as moderator. Data were distributed to a total of 250 young professional via online survey. After screening the returned questionnaires, a total of 211 questionnaires were acceptable and continued for further analysis. The finding shows that attitude and perceived behavioral control have a positive and significant relationship toward intention to use of mobile payment among young professionals. Whereas, subjective norm, perceived ease of use and perceived usefulness were found to be insignificant. Meanwhile, trust moderates the relationship between attitude and subjective norms toward intention to use mobile payment. The results from this study could help to inform marketers and mobile payment service providers about the significant factors that influence intention to use of mobile payment, so they can adapt their marketing strategies to suit the needs and wants of young professional in Malaysia.
\end{abstract}

Keywords: intention to use, trust, subjective norms, perceived ease of use, perceived usefulness, mobile payment

\section{INTRODUCTION}

The worldwide mobile payment services are in a up growing trend. However, as reported in Star Online in 2018, only less than $20 \%$ of Malaysian have processed their transactions by using mobile payment as compared to credit card or debit card which was famous and widely accepted payment mode or payment tools for the Malaysian. According to the surveys from the Visa Consumer Payment Attitudes Study in 2016, it shows low acceptance rate among the Malaysian as there are $83 \%$ of Malaysians who owning the smart phone aware about the existing of mobile payment application, and only $34 \%$ out of those users were uses the services before as reported by The Sun daily. Therefore, the usage of the mobile payment was relatively low as compared to mobile penetration rate in Malaysia.

These Mobile payment is an integration of mobile devices and payment services which is a digital wallet with the user's money being credited into the mobile application as digital to enable the same to function just like a physical wallet whereby the users can pay for their purchases without having the need to search through their physical wallet to present their value card or cash note physically to the vendors and the payment can be proceeded within second. With the advantages of the mobile payment application, the consumers can now focus on their priorities thus it brings tremendous convenience to the users which save their invaluable time and effort.

In 2017, Bank Negara Malaysia (BNM) has published out their 10-years financial sector blueprint 2011-2020 recently with the wish to reduce the amount of cheques issued per year and replace the same with mobile payment (cashless transaction). Therefore, the cashless market is predicted to gain popularity in usage of the same for the future market as Malaysia are estimated to become a cashless transaction country by the year 2022 whereby most of the cashless transaction users are those whose age ranging from 15-35 years old. As a result, there will be a lot of cashless service system to be created to cater and to fulfil the market demands to ease the payment for the purchases made and further to ensure its smoothness and effectiveness. According to some recent studies by Zion Market Research in 2017, the mobile phone or recently named as smart phone which is a popular and advance device which has been utilised enormously in recent market to achieve the cashless transaction purposes.

Therefore, the rapid growth of the wireless network service via smartphone (mobile maze) [1] has triggered the innovation of the human race to create a new competency to execute their business and marketing strategies through smartphone which called mobile payment (m-payment) which then promise of a bright future for the global business marketing [2] and become a catalyst to transform the global market from traditional approach to a more advance and systematic approach. Recently, the association of mobile operators (GSMA) study has reported out that the global cell-phone users had reaching a sum amount of five billion and estimated to have a huge increase soon as the market is expecting to welcome a new life-changing information technology services named as fifth generation network services $(5 \mathrm{G})$. With the scenario, development of the mobile payment facilities will provide more convenience to the consumers and also for the organizations who is running in the business [3].

With this optimistic trend, most of the organizations and government sectors had restructure their marketing strategy with better business plan and further improve their payment system into the mobile payment system to keep up with the current market trend. For instance, the world's famous 
retailer store, Wal-Mart Stores, Inc.'s (WMT) has invented their own mobile payment system, Walmart-pay and the same has been adopted and being in operation in their own stores. Besides that, the Starbucks Corporation (SBUX), the famous coffee brand retailer also come out with their own mobile payment that called Starbuck wallet app to capture the market behaviour. Further, Starbucks has also provided another option whereby their consumers can choose to pay by using Wechat-pay. In Malaysia, there are more than 10 mobile payment applications such as Samsung pay, Alipay, Favepay, Grabpay, Vcash, Maybank QR pay, TnG, etc. that actively provides mobile payment services. As such, the financial organizations such as the banking corporates in the worldwide scale have started to indulge themselves with the mobile transaction system and services. Therefore, the service providers are supported by the Malaysia financial institutions such as CitiBank, CIMB bank, Maybank, Standard Chartered Bank etc.

Theory acceptance model and Theory of planned behavior had been integrated to investigate this phenomenon. Five factors (perceived ease of use, perceived usefulness, attitude, subjective norms, perceived behavioral control) were tested on intention to use mobile payment. To begin the discussion, this paper is structured as follows. Subsequent to this introduction, Section 2 continues with a review of related literature in streams of research on attitude and behaviour as well as technology acceptance toward intention to use mobile payment. Section 3 briefly explains the method and data used, while Section 4 explains the empirical results as well as discusses the relevant implications and marketing consequences. The final section concludes the study.

\section{RESEARCH MODEL AND HYPOTHESIS DEVELOPMENT}

Existing literature review shows that the technology acceptance and consumers' behavioral played an important role and there is supported by the theory in the academic. Therefore, the theory has played a role to enable researchers to understand the practicality of their research [4] and contributed to the development of the research framework and hypothesis testing. There are two theories that enable to further study on the technology acceptance and consumers' behaviour towards the intention of usage of the mobile payment by the consumers which is Technology Acceptance Model (TAM) and Theory of Planned Behavioural (TPB). Both TAM and TPB were the extension from the origin Theory of Reasoned Action (TRA) which then further discussed about the behavioural culture among the society and has well interrelationships between these two theories which to describe about the external factors, attitude, beliefs, behavioural intention, the actual behaviour etc. [1]. Moreover, numerous of studies have evaluated on the relationship between these theories with the intention to use. Thus, the study was applied with the combination of TAM and TPB which moderated bu Trust as moderator variable. With this situation, it is useful for the future in term of theoretically and practically significant [5].

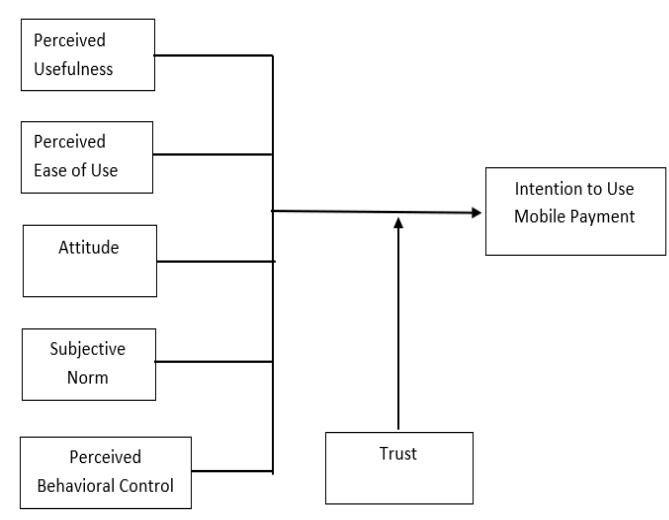

Fig. 1. The proposed theoretical framework.

\section{A. Theory Acceptance Model (TAM)}

Technology Acceptance Model (TAM) is a theory that well explained on the variation which affects the possibility of adoption of the new information and communication technology system whereby the TAM has always been used as the main or basic model for the researchers to refer on regarding the acceptance and adoption of the new technologies [6]. Evidently, the TAM is a well-known theory to be applied by the researchers on their studies pertaining to the new technology and service because of its applicability and simplicity [7]. In additional, perceived ease of use (PEOU) and Perceived usefulness (PU) are the well-known determinants in the TAM model that used to explain the technology acceptance and consumer behavioural.

Perceive ease of use is a determinant from TAM that to explain on 'how those people believe on certain applications or tools that applied in their daily life were not present in the attempt' [8]. Due to the market demands, there are lots of innovative and creativity the technologies services and devices that available in the market. For instances, the mobile phone which was meant to serve as a device for communication (either to make a call or to receive a call) during its early stage was then improved by implementing the mobile phone with more functions and features together with new application being able to be installed unto the mobile phone whereby the latest mobile phone is now known as smartphone is equipped with more advance applications and features such as GPS, gaming, internet browsing, video streaming, voice call, video call, mobile commerce, mobile wallet, mobile payment etc. [9]. However, this has yet to satisfy the users and the quest to continue to search for a device or service which promotes convenience and ease to use is still on. Thus, the continuous enhancement of mobile technologies has enable the organizations and the consumers to assess or to perform their daily tasks in a shorter period of time easily [9]. As a result, the perceived ease of use is used as determinant in the study as it is a 'design to understand on one of system that become the inhibitor to discourage the adoption of an innovation' [10] and there were some arguments on whether the perceived ease of use is the main factor that influence the intention of use of mobile payment. Therefore, there is first hypothesis been developed to examine on the relationship between perceived ease of use and intention to use of the mobile payment. 
H1. There is a positive and significant relationship between perceived ease of use and intention to use.

Perceived usefulness is one of the determinant explain on the humans' behavioural and person believes as defined as "the degree to which a person believes that using a particular system would enhance his or her job performance" [11]. Therefore, the perception was the behavioural or attitude that always influence people to make decision in purchasing a good or to engage the services due to its appearance and further will have a high impact towards the consumers based on their preferences [3]. Perceived usefulness was a significant factor to determine acceptance on the usage of mobile payment services and new information technologies in their studies [12], and the study also showed that the intention to accept the usage of the mobile services was significantly influenced with perceived usefulness [12]. According to the past studies, there is a positive response on the determinant perceived usefulness towards the intention to use of new technologies. Thus, a hypothesis was developed to examine on the relationship between perceived usefulness and intention to use mobile payment.

H2. There is a positive and significant relationship between perceived usefulness and intention to use.

\section{B. Theory of Planned Behavior}

Theory of planned behaviour (TPB) is a theory that extended from the Theory of Reasoned Action (TRA) which is widely used in explaining the consumer behaviour [13]. TPB mainly focused on the perceived behavioural control that refers to 'individual perception of the ease to have a well control of the behaviour' [14] and it is well related to the behavioural intention (Thakur \& Srivastava, 2014). This theory also well explained and being used to study on the acceptance and influences of the new information technology such as social media, network, mobile payment application, etc. (Cameron, 2010) which is suitable to measure the behavioural intention [15] and it is comprehensive and covering of three dimensions (attitude, subjective norms and perceived behavioural control) that is well-known theory to explain on the human behaviour and intention to use.

The attitude is a variable that has been measured in the model of Theory of Planned Behaviour, attitude has a high correlation to the behavioural intention and tend to drive to the verbal response and overt actions [16]. Attitudes can be predicted accurately by different kind of behaviours [16]. Therefore, the attitude has always been considered together with the behaviour of influence in the theory of the behavioural. Other than that, consumer behaviour is also significantly affected by one's intention whereas such intention was driven by the one's attitude [17] and has significant relationship with the personal behaviour of a human being [18]. From the literature review, several studies of behavioural intention from previous have indicated that the attitude is an important factor to be examined [13] and resulted a positive response towards such measurable variable. As a result, a hypothesis has been developed to examine whether the attitude has a significant variable and to measure on strength of the intention to use among the young professional.
H3. There is a positive and significant relationship between attitude and intention to use.

Subjective norms were used to study on the intentions to use with the definition, 'perception of a person thought and opinion of the individual's action and decision making [19] and the behaviour can be an influencing from external and motivation to make according to the wishes of the references' [16]. Therefore, the subjective norms are important predictor to determine the behaviour intention which is fragile [20] and higher tendency of being influenced by their peers among the younger users in accepting and adopting the m-payment services [12] because the social influence or external influence always reacted as a major key factor towards the acceptance of the new technology especially during the initial launching stage [21]. As according to previous study, there are a lot of advertisement in the mobile applications which are constantly aims to influence the users who own a mobile phone whereby it has been seen to have more advantages and user friendly in influencing the mind of the users. Thereafter, the consumers who have been exposed to such advertisement may conduct their own research through the internet or to visit to the dealer or retail shop or discuss with their friend to explore or to gain more information on the new information technology system and hence encourages the acceptance of the same. As such, the subjective norms are forecast to be a probable variable to determine the intention to use of mobile payment whereby it explains on the consumer behaviour as below hypothesis.

H4. There is a positive and significant relationship between subjective norms and intention to use.

Further on, perceived behavioural control is the third variable in TPB that explained on the beliefs of control [13] which is a significant factor to the intent of behaviour for consumers to perform online purchases [22] and have suggested that a good experience on the previous experience will impact the consumers to have more intent to use [23]. Therefore, this has led to hypothesis between perceived behavioural control and intention to use mobile payment.

H5. There is a positive and significant relationship between perceive behavioural control and intention to use.

\section{Trust as moderator}

Trust towards the new information and communication technology system was an important key parameter to make sure the consumers get satisfaction of the same [24] and minimized their risk of using mobile payment during the transaction [2]. In previous study, there were several of studies regarding new information and communication technology system and behaviour intention which have showed a positive relationship [25]. Therefore, in order to accept the mobile payment system, the accountable parties were required to obtain and display the recognized certificate issued by the relevant authorities to the public to gain the trust of the public at large [26] and prominent influential effect towards the intent to use mobile payment for the youngsters [27]. According to the literature review, trust was acted as important moderator variable to the independent variable on the acceptance of new technologies and applications. Thus, trust and individual privacy issues 
were the main concern for consumers to use mobile payment [3], and the hypotheses were then created to examine whether trust has a moderating effect relationship between the independent variables (perceived ease of use, perceived usefulness, attitude, subjective norms, and perceived behavioural control) and the dependent variable (intention to use). Accordingly, the study proposes the following hypothesis which is moderating by trust as moderator variable:

H6. Trust moderates the relationship between perceived ease of use and intention to use mobile payment.

H7. Trust moderates the relationship between perceived usefulness and intention to use mobile payment.

H8. Trust moderates the relationship between attitude and intention to use mobile payment.

H9. Trust moderates the relationship between subjective norms and intention to use mobile payment.

H10. Trust moderates the relationship between perceived behaviour control and intention to use mobile payment.

\section{METHODOLOGY}

To collect the data for the study, a survey questionnaire based on a five-point Likert scale, ranging from 1 (strongly disagree) to 5 (strongly agree) was designed and then distributed toward young professional in Malaysia. The data was collected through an online survey. The survey form was designed with filter questions which aimed to filter out respondents who are not young professionals. The young professional group are those in the ages of 20-40 (20 is minimum ages to achieve the Diploma certificate in Malaysia). Owned at least a Diploma and above or equivalence professional qualification certification, and currently serves in the professional field. A total of 220 complete questionnaires were returned and only 211 were acceptable for further analysis.

\section{RESULT}

Table 1 illustrates the profile of respondents in this study. Data were gathered from all around Malaysian states via online survey, most of the respondent however coming from Penang state $(51.2 \%)$. It consists with 55 per cent of male and 45 per cent of female young professionals. Most of them are Bachelor Degree or Equivalent holder (55.9\%) and working as business and administration professional (37.9\%). 73 per cent of the respondents working in private sectors and are single (60.2\%). They have used online payment at least once a month $(51.2 \%)$.

\section{A. Descriptive analysis}

Table 2 presented the summary of the descriptive analysis statistics. The descriptive analysis is reflected the respondents' perspectives toward the questions that being asked in the survey questionnaire. 5-point Likert scale was used in the survey questionnaire which is from 1 (strongly disagree) to 5 (strongly agree). The mean below 3.0 is considered low, and 3.0 is average, while above 3.0 is high. From the descriptive statistics data, found that most of the data were above 3.5 except two variables (subjective norms and trust), which is at between 3.0 to 3.5. Next is the standard deviation data which is at the range of 0.7 to 0.9 mean it is a greater spread data. The perceived ease of use $(\mathrm{M}=3.99, \quad \mathrm{SD}=0.73)$, perceived usefulness $(\mathrm{M}=4.01$, $\mathrm{SD}=0.73)$, attitude $(\mathrm{M}=3.78, \mathrm{SD}=0.91)$, subjective norms $(\mathrm{M}=3.30, \mathrm{SD}=0.81)$, perceived behavioral control $(\mathrm{M}=3.84$, $\mathrm{SD}=0.75)$, trust $(\mathrm{M}=3.27, \mathrm{SD}=0.93)$, intention to use $(\mathrm{M}=3.74, \mathrm{SD}=0.86)$. In summary, the young professional perceived higher level of majority determinants (perceived ease of use, perceived usefulness, attitude, perceived behavioral control and intention to use), and slightly above level for the subjective norms and trust.

TABLE 1. RESPONDENT PROFILE

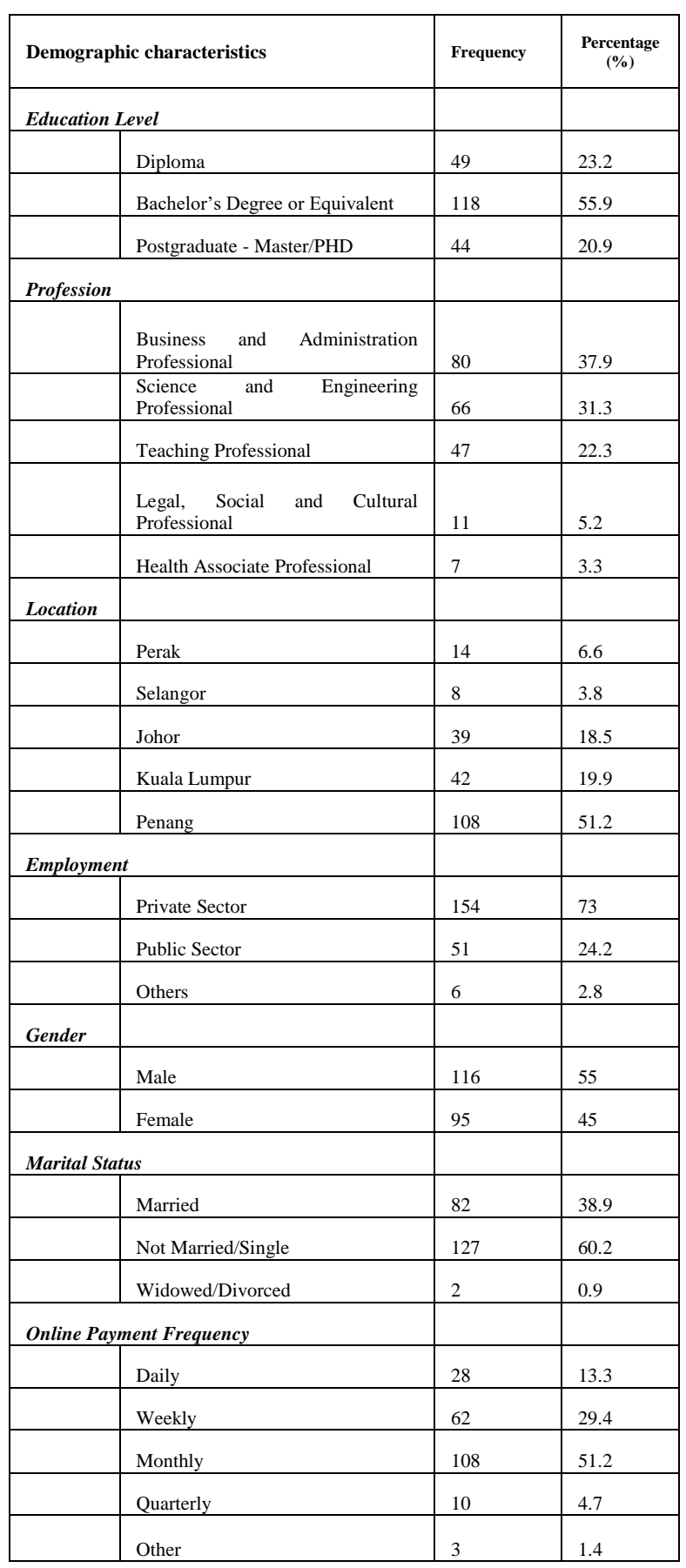


TABLE 2. DESCRIPTIVE AND RELIABILITY ANALYSIS RESULTS

\begin{tabular}{|l|l|l|l|}
\hline Variables & $\begin{array}{l}\text { Cronbach } \\
\text { Alpha }\end{array}$ & Mean & SD \\
\hline $\begin{array}{l}\text { IV - Perceive ease of use } \\
\text { (PEOU) }\end{array}$ & 0.92 & 3.99 & .73 \\
\hline $\begin{array}{l}\text { IV - Perceive usefulness } \\
\text { (PU) }\end{array}$ & 0.92 & 4.01 & .73 \\
\hline $\begin{array}{l}\text { IV - Attitude (ATT) } \\
\text { IV - Subjective norms } \\
\text { (SN) }\end{array}$ & 0.97 & 3.78 & .91 \\
\hline $\begin{array}{l}\text { IV - Perceive behavioural } \\
\text { control (PBC) }\end{array}$ & 0.92 & 3.84 & .75 \\
\hline $\begin{array}{l}\text { MV - Trust (T) } \\
\text { DV - Intention to use } \\
\text { (INT) }\end{array}$ & 0.95 & 3.74 & .86 \\
\hline
\end{tabular}

\section{B. Multiple regression analysis}

The multiple regression analysis was carried out after the factor analysis was done to determine the relationship between variables. Table 3 shows two variables (attitude and perceived behavioural control) have a positive and significant relationship toward intention to use with $(\beta$ $=0.555, \mathrm{t}=6.389, \mathrm{p}<0.001)$ and $(\beta=0.139, \mathrm{t}=1.995, \mathrm{p}<0.05)$ and the VIF more than 1.0. Subsequently, for the moderating of trust, there were two variables were significant, which attitude and subjective norms $(\beta=0.187$, $\mathrm{t}=2.211, \mathrm{p}<0.05)$ and $(\beta=-0.242, \mathrm{t}=3.064, \mathrm{p}<0.05)$ and the VIF more than 1.0.

\section{DISCUSSION AND CONCLUSION}

Attitude and perceived behavioural control were the two factors that significant and positively influence the intention to use among young professional toward mobile payment in Malaysia. Additionally, trust moderates the relationship between subjective norms and attitude and intention to use. However, the perceived ease of use and perceive usefulness were found to be insignificant. Thus, it can be stated that hypothesis 3 , hypothesis 5, hypothesis 8 and hypothesis 9 are supported. Whereas, hypothesis 1, hypothesis 2, hypothesis 6 , hypothesis 7 and hypothesis 10 are found to be not supported.

The finding of this study was inconsistent with previous study, which found that subjective norms, perceived usefulness and perceived ease of use were among of the predictors of consumer intention to use mobile payment [25] however, the significant relationships between attitude and perceived behavioral control were in line with previous study [13].
This study implies that, significant factors such as attitude, perceived behavioral control, trust should be instill and adapted in the marketing strategies of marketers or mobile service provider. This could help them to meet the needs and wants of young professionals in Malaysia.

TABLE 3. MulTiPle REgRESSION ANALYSIS

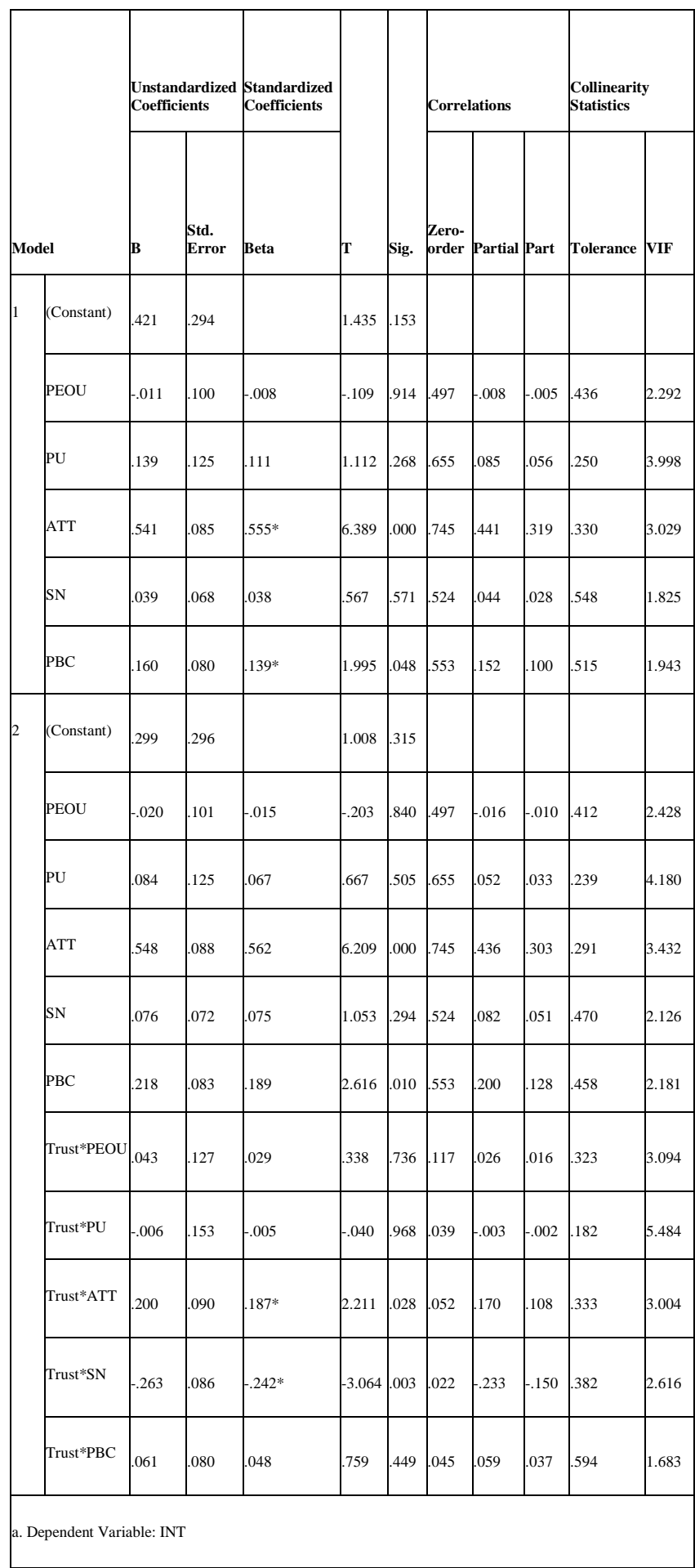

On the other hand, firms should cooperate with the government to organize programs related to mobile payment or encourage their young professional staff to 
engage with this program. This could influence their attitude and behaviour toward mobile payment and will have a positive attitude to use mobile payment as these methods will ease their everyday transactions and matching with their lifestyle [28].

Service provider must play the role to increase the acceptance of mobile payment among young professional. For example, engaged with some retailers or organization to provide the promotion or cash rebate when they pay their purchase with mobile payment apps. Moreover, trust as moderator also observed a significant and positive relationship between subjective norms and intention to use. Therefore, the service providers must make sure their services are trustee so the users who trust the services will start to influence their peers which will be effectively increase the acceptance of the mobile payment services among the young professional.

As a conclusion, it is hoped this study has provided valuable information to the many parties such as government sectors, private sectors and NGO in order to help them to implement or to expend their mobile payment system. In addition, the researchers also can make use of this data for their future references. This study also contributes to the body of literature the integration between both theories TAM and TPB.

\section{REFERENCES}

[1] Chen L, Chin F-G., Sun Y and Rasli A. "Integrating guanxi into technology acceptance: An empirical investigation of WeChat". Telematics and Informatics, 34(11), 25-42, 2017

[2] Madan K and Yadav R. "Behavioural intention to adopt mobile wallet: a developing country perspective", J. Indian Business Research, 8 (2), 27-44, 2016

[3] Singh N, Srivastava S and Sinha N. "Consumer preference and satisfaction of M-wallets: a study on North Indian consumers". International Journal of Bank Marketing, 35(9),44-65, 2017

[4] Zikmund W G, Babin B J, Carr J C and Griffin M. Business Research Methods. 9th Edition. South-Western Cengage Learning, 2013

[5] Slade E L, Dwivedi Y K, Piercy N C and Williams M D. Slade EL, Dwivedi YK, Piercy NC, Williams MD. "Modeling consumers" adoption intentions of remote mobile payments in the United Kingdom: extending UTAUT with innovativeness, risk, and trust". Psychology \& Marketing, 32(8),60-73, 2015

[6] Dulcic Z, Pavlic D, Silic I. Evaluating the intended use of Decision Support System (DSS) by applying Technology Acceptance Model (TAM) in business organizations in Croatia. Procedia-Social and Behavioral Sciences. 2012 Oct 12;58:1565-75.

[7] Phonthanukitithaworn C, Sellitto C and Fong W L. "An investigation of mobile payment (m-payment) services in Thailand". Asia-Pacific Journal of Business Administration. 2016 Apr 4

[8] Nejad MG, Apanasevic T, Markendahl J, Arvidsson N. Stakeholders' expectations of mobile payment in retail: lessons from Sweden. International Journal of Bank Marketing. 2016 Feb 1.

[9] Daştan İ, Gürler C. "Factors affecting the adoption of mobile payment systems: An empirical analysis". Emerging Markets Journal,6(1):17-24, 2016 Feb 2

[10] Wei T-W, Marthandan G, Chong A Y-L, Ooi K-B and Arumugum S. "What drives Malaysian M-commerce adoption? An empirical analysis" Industrial Management \& Data Systems, 109(3)70-88, 2009

[11] Fayad R and Paper D. "The technology acceptance model ecommerce extension: a conceptual framework. Procedia Economics and Finance", 26 1000-06, 2015.

[12] Koenig-Lewis N, Marquet M, Palmer A and Zhao A L. "Enjoyment and social influence: predicting mobile payment adoption". The Service Industries Journal,35(10):537-54, 2015 Jul 27

[13] Ting H, Yacob Y, Liew L and Lau W-M. "Intention to use mobile payment system: a case of developing market by ethnicity". Procedia-Social and Behavioral Sciences, 224:368-75, 2016 Aug

[14] Lai PC. "The literature review of technology adoption models and theories for the novelty technology". Journal of Information Systems and Technology Management, 14(1):21-38, 2017

[15] Thakur R and Srivastava M. "Adoption readiness, personal innovativeness, perceived risk and usage intention across customer groups for mobile payment services in India”. Internet Research, 24, 369-92, 2014

[16] Ajzen I. "The theory of planned behavior". Organizational behavior and human decision processes, 50(2):179-211, 1991

[17] Ünal S, Ercis A, Keser E. Attitudes towards mobile advertising-A research to determine the differences between the attitudes of youth and adults. Procedia-Social and behavioral sciences, 24:361-77, 2011.

[18] Gopi M and Ramayah T. "Applicability of theory of planned behavior in predicting intention to trade online". International Journal of Emerging Market, 2(3)48-60, 2007

[19] Ajzen I, Fishbein M, Albarracin D, Johnson BT, Zanna MP. The handbook of attitudes. Mahwah, NJ, US: Lawrence Erlbaum Associates Publishers, 173-221, 2005

[20] Lai PC. "Design and Security impact on consumers' intention to use single platform E-payment. Interdisciplinary Information Sciences, 22(1):111-22, 2016

[21] Jimenez $\mathrm{N}$ and Sonia S. "Attitude toward m-advertising and $\mathrm{m}$ repurchase". European Research on Management and Business Economics, 23(2):96-102, 2017.

[22] Khatimah H, and Halim F. "The effect of attitude and its decomposed, perceived behavioral control and its decomposed and awareness on intention to use e-money mobile in Indonesia. Journal of Scientific Research and Development", 3(1):39-50, 2016.

[23] Cobanoglu C, Yang W, Shatskikh A, and Agarwal A. "Are consumers ready for mobile payment? An examination of consumer acceptance of mobile payment technology in restaurant industry". Hospitality Review,31(4):6, 2015.

[24] Masrek MN, Mohamed IS, Daud NM, and Omar N. "Technology trust and mobile banking satisfaction: a case of Malaysian consumers". Procedia-Social and behavioral sciences, 129:53-8, 2014.

[25] Munoz-Leiva F, Climent-Climent S, and Liébana-Cabanillas F. "Determinants of intention to use the mobile banking apps: An extension of the classic TAM model". Spanish Journal of Marketing-ESIC, 21(1):25-38, 2017.

[26] Eze UC, Gan GG, Ademu J, and Tella SA. "Modelling user trust and mobile payment adoption: a conceptual Framework". Communications of the IBIMA, 3(29):224-31, 2008.

[27] Shaw N. "Younger Persons are More Likely to Adopt the Mobile Wallet than Older Persons, or are they? The Moderating Role of Age". Twenty-first Americans Conference on Information Systems Puerto Rico, 2015

[28] Ozturk AB, Bilgihan A, Salehi-Esfahani S, and Hua N. "Understanding the mobile payment technology acceptance based on valence theory". International Journal of Contemporary Hospitality Management, 29,2027-2049, 2017. 